\title{
Clinical and molecular features of three patients with congenital disorders of glycosylation type Ih (CDG-Ih) (ALG8 deficiency)
}

\author{
E Schollen, C G Frank, L Keldermans, R Reyntjens, C E Grubenmann, P T Clayton, B G Winchester, \\ J Smeitink, R A Wevers, M Aebi, T Hennet, G Matthijs
}

$\mathrm{P}$ rotein glycosylation is an essential post-translational modification of various proteins, affecting their folding, sorting, and function. Inborn defects in the assembly and processing of glycans on glycoproteins are known as congenital disorders of glycosylation (CDG) and can affect both N- and O-glycosylation (for reviews see Marquardt and Denecke, ${ }^{1}$ Jaeken, ${ }^{2}$ and Grunewald et al ${ }^{3}$ ). N-glycosylation defects and especially defects in the assembly of the dolichol linked N-glycan precursor in the endoplasmic reticulum (ER) (CDG-I) result in hypoglycosylation of many kinds of (serum) glycoproteins. CDG-I is therefore a group of multisystemic disorders.

The assembly of the $\mathrm{N}$-glycan precursor in the ER is a highly ordered process involving at least 30 known gene products. Mutations in 11 of these (PMM2, MPI, ALG6, DPM1, ALG3, MPDU1, ALG12, ALG8, ALG2, DPAGT1, and ALG1) have been shown to cause CDG type I (CDG-Ia to CDG-Ik). ${ }^{2-10}$ Although it remains difficult to define a characteristic clinical phenotype for each type of CDG, mainly because only a limited number of patients have been assigned to most types, they generally share hypotonia and different degrees of mental retardation. Central nervous system defects are absent in CDG-Ib patients (with a deficiency of phosphomannose isomerase, MPI) and in the recently published CDG-Ih patient (with a deficiency of dolichyl-PGlc: Glc $_{1}$ Man $_{9}$ GlcNAc$_{2}$-PP-dolichyl $\alpha$ l, 3-glucosyltransferase, ALG8). ${ }^{4}$ CDG-Ib patients present mainly with hypoglycaemia, coagulopathy, hepatomegaly, protein-losing enteropathy, hepatic fibrosis, cyclic vomiting, and diarrhoea. ${ }^{11-14}$ It is the only type with an efficient therapy because dietary mannose can be used via an alternative pathway to generate mannose6-phosphate that is normally produced from fructose-6phosphate by the action of MPI.

The only CDG-Ih patient described so far shares this relatively mild presentation with severe diarrhoea and moderate hepatomegaly. ${ }^{4}$

Our cohort of unsolved CDG patients included three patients from two families with an ALG8 deficiency, which also classified them as CDG-Ih (OMIM \#608104). All three patients presented with a severe clinical phenotype resulting in early infant death. One of them, patient GB0243, was the first CDG-I patient reported with the characteristic hypoglycosylation of serum proteins but without a deficiency of phosphomannomutase. ${ }^{15}$ We describe here the clinical, biochemical, and molecular features of the three patients.

\section{METHODS}

\section{Cell culture}

Primary fibroblasts obtained from skin biopsies were cultured in Dulbecco's Modified Eagle's Medium (DMEM/F12, Gibco) with $4.5 \mathrm{~g} / \mathrm{l}$ glucose and $10 \%$ fetal calf serum (FCS). To block $\alpha$-glucosidase-I activity, cells were cultured in the presence of

\section{Key points}

- Congenital disorder of glycosylation type Ih (CDG-Ih) is caused by a defect in the dolichyl-P-Glc:Glc Man, ${ }_{9} \mathrm{GlNAc}_{2}$-PP-dolichyl $\alpha 1,3$-glucosyltransferase (ALG8). Thus far, the only patient has been described with a relatively mild clinical picture.

- We describe the molecular and clinical features of three patients from two families with an ALG8 deficiency. All three patients presented with severe, life-threatening multi organ failure and died within their first months of life.

- Diagnosis of CDG-lh was based on the accumulation of the lipid-linked oligosaccharyl intermediates dol-PP$\mathrm{GlcNAc}_{2} \mathrm{Man}_{9}$ and dol-PP-GlcNAc${ }_{2} \mathrm{Man}_{9} \mathrm{Glc}_{1}$ in patients' fibroblasts. Mutation analysis of the ALG8 gene identified in both families a compound heterozygosity for a splice site mutation and a missense mutation (family 1: c.96-2A>G and p.T47P; family 2: c. $672+4 A>G$ and p.G275D). The functional effect of the ALG8 splice mutations was analysed on mRNA and the effect of the missense mutations was assayed in ALG8 deficient yeast strains.

- CDG-lh patients present with severe hepato-intestinal problems, and the clinical spectrum ranges from mild to very severe, including neonatal death. Central nervous system defects have not been observed in the four known patients.

$250 \mu \mathrm{M}$ castanospermine (CST) (Calbiochem) for $2 \mathrm{~h}$, prior to labelling." The effect of the splice site mutations was investigated on cells grown for $16 \mathrm{~h}$ in the presence of $200 \mu \mathrm{g} / \mathrm{ml}$ puromycin (Sigma) to block nonsense-mediated mRNA decay. ${ }^{16}$

\section{Lipid-linked and protein $\mathrm{N}$-linked oligosaccharide (LLO, NLO) analysis}

LLO and NLO analyses were performed on extracts from fibroblasts as described in Grubenmann et al. ${ }^{2}$ In brief, fibroblasts (about $450 \mathrm{~cm}^{2}$ ) were grown to $90 \%$ confluence and labelled with $150 \mu \mathrm{Ci}\left[{ }^{3} \mathrm{H}\right]$ mannose for $\mathrm{l} \mathrm{h}$. LLOs were recovered from the cell suspension with

Abbreviations: CDG, congenital disorders of glycosylation; CPY, carboxypeptidase Y; CST, castanospermine; ER, endoplasmic reticulum; LLO, lipid-linked oligosaccharide; MPI, phosphomannose isomerase; NLO, N-linked oligosaccharide; NMD, nonsense-mediated mRNA decay 
chloroform:methanol: $\mathrm{H}_{2} \mathrm{O}$ extraction. Oligosaccharides released by mild acid hydrolysis from LLOs or by PNGaseF treatment of the residual pellet (NLOs) were then analysed by HPLC.

\section{Mutation analysis of ALG8}

Primers were designed to amplify the 13 exons of ALG8, including at least $50 \mathrm{bp}$ of the flanking intronic regions, based on the genomic sequence of ALG8 (NT_033927.5 region 8011022.8049713). Primer sequences are available on request. The exons were amplified using standard PCR conditions, subsequently sequenced with Big Dye Terminator Ready reaction cycle sequencing kit V3.1 (Applera) and analysed on an ABI3100 Avant (Applera).

Frequency of the polymorphism c.665A $>$ G (p.N222S) The polymorphism c.665A $>\mathrm{G}$ creates an Hpy8I restriction site. Exon 6 was amplified from genomic DNA of a panel of 50 healthy individuals (Caucasians). A 10- $\mu$ l sample of PCR product was subsequently digested with Hpy8I (Fermentas) and analysed on a $2 \%$ agarose gel.

\section{RT-PCR}

Total RNA was isolated from patients' fibroblasts and a normal control using Trizol (Invitrogen) according to the manufacturer's protocol. cDNA was prepared with oligo-dT priming and Superscript II RNAse-H reverse transcriptase (Invitrogen) using $20 \mu \mathrm{g}$ total RNA in a total volume of $80 \mu \mathrm{l}$.

To analyse the effect of the splice mutations, the ALG8 sequence was amplified from cDNA with primers ALG8-1F (5'-TGG ATC AAG TTG GTG GGA AG) and ALG8-2R (5' - TTA CAG CAC TCA CGG ACA GC) for GB0243 and primers ALG82F (5' - TTT TCC AGA GAT TTT CCG TCA) and ALG8-4R (5' CAA AAG GCT CAT TGG GAG AA) for NL0097. A 2- $\mu$ l cDNA sample was used in a total volume of $50 \mu \mathrm{l}$ with Taq DNA polymerase (Roche). Amplification conditions were 2 min at $94^{\circ} \mathrm{C}, 10$ cycles of $20 \mathrm{~s}$ at $94^{\circ} \mathrm{C}, 30 \mathrm{~s}$ at $65^{\circ} \mathrm{C}\left(-1{ }^{\circ} \mathrm{C}\right.$ each cycle $)$ and $1 \mathrm{~min}$ at $72^{\circ} \mathrm{C}$ followed by 25 cycles of $20 \mathrm{~s}$ at $94^{\circ} \mathrm{C}, 30 \mathrm{~s}$ at $55^{\circ} \mathrm{C}$, and 1 min at $72^{\circ} \mathrm{C}$.

\section{Cloning of ALG8 in expression vectors}

For cloning of the ALG8 coding sequence in a yeast expression vector, ALG8 was amplified with primers ALG8IF and ALG8-1R ( $5^{\prime}$-GCA GTT CCT TTA TTC ATT GTT TCT T) using $2 \mu \mathrm{l} \mathrm{cDNA}$ in a total volume of $50 \mu \mathrm{l}$ with Pwopolymerase (Roche). The cycling conditions were $2 \mathrm{~min}$ at $94^{\circ} \mathrm{C}, 10$ cycles of $15 \mathrm{~s}$ at $94^{\circ} \mathrm{C}, 30 \mathrm{~s}$ at $60^{\circ} \mathrm{C}$, and $90 \mathrm{~s}$ at $68^{\circ} \mathrm{C}$, followed by 20 cycles using the same conditions but increasing the extension time every cycle by $5 \mathrm{~s}$. After amplification, $1 \mathrm{U}$ Taq polymerase (Roche) was added and the mixture was incubated at $72^{\circ} \mathrm{C}$ for $7 \mathrm{~min}$ to allow subsequent TA cloning.

A 2- $\mu$ l sample of the ALG8 amplicon from GB0243, NL0097, and a normal control were cloned in pCR2.1 using the TA cloning kit (Invitrogen). Constructs were selected for the right orientation and inserts were sequenced in both directions. The wild type and the T47P ALG8 constructs both encode a serine (S) at position 222 while the G275D construct encodes an asparagine $(\mathrm{N})$. The ALG8 inserts were then subcloned as BamHI/XhoI fragments in the BamHI/XhoI sites of $\mathrm{p} 426 \mathrm{GPD},{ }^{17}$ placing them under the control of the strong glyceraldehyde-3-phosphate dehydrogenase promoter.

\section{Yeast strains and media}

$S$. cerevisiae strains used in this study were derivatives of YG98-1d (MATa Aalg8::HIS3 ade2 his3 ura3 leu2 tyrl wbpl-1; the NNAR motif of Wbplp is mutated to NNAY, CG Frank, unpublished results) and YG127 (MATa Aalg8::HIS3 ade2 ura3 tyrl lys2)..$^{18}$ Standard yeast media and genetic techniques were used. ${ }^{19}$ Strain YG98-1d and its transformants were propagated at $23^{\circ} \mathrm{C}$ and strain YGl27 and its transformants at $30^{\circ} \mathrm{C}$.

\section{Complementation assays}

Western blot analysis of the carboxypeptidase Y glycoprotein (CPY) was performed as described previously. ${ }^{20}$ Temperature sensitivity of yeast strains was assessed on full medium (YPD) plates. For the dilution series, $5 \mu \mathrm{l}$ of serial 10 -fold dilutions of YG98-1d transformants, grown in selective medium for $48 \mathrm{~h}$, were spotted starting at $5 \times 10^{5}$ cells $/ 5 \mu \mathrm{l}$. Plates were incubated at $23^{\circ} \mathrm{C}, 29^{\circ} \mathrm{C}$ and $30^{\circ} \mathrm{C}$ for $96 \mathrm{~h}$.

\section{RESULTS}

\section{Case reports}

The clinical and standard laboratory data of patient GB0243 were previously described in detail by Charlwood and colleagues. ${ }^{15}$ In brief, GB0243, the first child of healthy, unrelated Caucasian parents, showed intrauterine growth retardation, oligohydramnios, and reduced fetal movements. For the first 4 weeks of life he was sleepy, and difficult to feed with failure to thrive. He then developed diarrhoea, vomiting, and abdominal distension due to massive ascites. Routine investigations indicated anaemia and a marked tubulopathy. No arguments for CNS involvement were found based on clinical examination and cranial imaging. Despite intensive treatment with antibiotics, oxygen, diuretics, paracentesis, transfusions, electrolyte supplements, and thyroxine, he showed no real improvement and died at the age of 3 months. His sister (GB0244), conceived 4 years later, also showed poor growth in utero and reduced fetal movements. She became oedematous with electrolyte disturbance within hours of birth and died 3 days later.

Patient NL0097 was born prematurely ( 35 weeks) after an uncomplicated pregnancy, immediately presenting poor cardio-respiratory conditions possibly due to lung hypoplasia. Clinical examination revealed several dysmorphic features: asymmetric skull, wide open large fontanel, hypertelorism, low-set, abnormally positioned ears, long philtrum, short neck, cryptorchism, camptodactyly of the third and fourth fingers of both hands, and club feet. Multiple haematomas and petechiae were present. Biochemical investigations showed low haemoglobin level of $6.1 \mathrm{mM} / \mathrm{l}$, severe thrombocytopenia ( $\left.18 \times 10^{9} / \mathrm{l} ; \mathrm{nl} 150-400\right)$, and primary hypothyroidism. Cardiological investigation revealed a perimembranous and trabecular ventricular septum defect as well as a patent ductus. At 16 days the patient had not yet regained his birth weight. There was no significant vomiting or diarrhoea. From 8 weeks on, a progressive ascites occurred leading to secondary complications including tachypnoea and dyspnoea. Despite all attempts, the disease course worsened and the patient died at the age of 3 months. Pathological studies revealed thorax and bilateral lung hypoplasia, multiple cystic dilated intra- and extrahepatic bile ducts, cholestasis, bilateral microcysts in all parts of the kidney, and absence of extramedular haematopoiesis. No central nervous system abnormalities were observed either on functional or anatomical basis.

An overview of the clinical presentation of the three patients described in this paper in comparison with patient MP (described by Chantret $e t a l^{4}$ ) and the typical presentations of CDG-Ia and CDG-Ib are given in table 1.

\section{Diagnosis of CDG}

Both patients showed an abnormal glycosylation of serum transferrin on isoelectric focusing with increased asialo and disialottransferrin, indicative for CDG type I. Phosphomannomutase (PMM) and phosphomannose isomerase (MPI) activities measured in cultured fibroblasts were 
Table 1 Clinical picture of four CDG-Ih patients compared with the typical CDG-la and Ib presentation

\begin{tabular}{|c|c|c|c|c|c|c|}
\hline Patient ID & GB0243 ${ }^{15}$ & $\begin{array}{l}\text { GB0244 (sib of } \\
\text { GB0243) }\end{array}$ & NL0097 & $\mathrm{MP}^{4}$ & CDG-la & CDG-Ib \\
\hline Sex & $M$ & $\mathrm{~F}$ & M & $\mathrm{F}$ & & \\
\hline $\begin{array}{l}\text { Reduced fetal } \\
\text { movements }\end{array}$ & + & + & - & & - & - \\
\hline Oligohydramnios & + & + & - & & - & - \\
\hline $\begin{array}{l}\text { Intrauterine growth } \\
\text { retardation }\end{array}$ & + & & - & & - & - \\
\hline $\begin{array}{l}\text { Cardiorespiratory } \\
\text { problems }\end{array}$ & + & + & + & & & \\
\hline Dysmorphic & + & + & + & & $-\rightarrow+$ & - \\
\hline Oedema & + & + & + & + & & \\
\hline Diarrhoea & + & & - & + & $-\rightarrow+$ & $+/++$ \\
\hline Vomiting & + & & - & & $-\rightarrow+$ & $+/++$ \\
\hline Ascites & + & & + & + & $-\rightarrow+$ & ++ \\
\hline Central hypotonia & + & + & + & & $+\rightarrow++$ & $-\rightarrow+$ \\
\hline Anaemia & + & & + & & & $-\rightarrow+$ \\
\hline Thrombocytopenia & + & + & + & & & \\
\hline Hypoalbuminaemia & + & + & + & + & + & ++ \\
\hline Coagulopathy & + & + & & + & + & + \\
\hline Electrolyte disturbance & + & + & + & & & \\
\hline Raised creatinine & + & + & & & & \\
\hline Low thyroxine & + & & + & & & \\
\hline $\begin{array}{l}\text { Abnormal } \\
\text { electroretinogram }\end{array}$ & & & - & + & Retinitis pigmentosa & - \\
\hline Outcome & Died at 3 months & Died at 3 days & Died at 3 months & $\begin{array}{l}\text { Required parenteral } \\
\text { nutrition, albumin } \\
\text { infusions. Alive at } \\
3 \text { years. Normal } \\
\text { development }\end{array}$ & Mild to severe & Mild to severe \\
\hline
\end{tabular}

normal, thus excluding CDG-Ia and CDG-Ib. Analysis of $\left[{ }^{3} \mathrm{H}\right]$ mannose labelled lipid-linked oligosaccharides (LLOs) from patients' fibroblasts revealed accumulation of dolPPGlcNAc $_{2} \mathrm{Man}_{9}$ and dol-PP-GlcNAc ${ }_{2} \mathrm{Man}_{9} \mathrm{Glc}_{1}$ in variable ratios (fig lA). Blocking the glucosyltransferase-glucosidase shuttle ${ }^{41}$ with the ER glucosidase inhibitor castanospermine (CST) prior to LLO analysis resulted in a single peak of dolPP-GlcNAc $\mathrm{Man}_{9} \mathrm{Glc}_{1}$ on LLO analysis of fibroblasts from patient NL0097 (fig 1B). For patient GB0243 the effect of CST is less clear: the dol-PP-GlcNAc $\mathrm{Man}_{9}$ intermediate is decreased while the dol-PP-GlcNAc${ }_{2} \mathrm{Man}_{9} \mathrm{Glc}_{1}$ and dol-PP$\mathrm{GlCNAc}_{2} \mathrm{Man}_{9} \mathrm{Glc}_{3}$ peaks are markedly increased (fig $1 \mathrm{~B}$ ). Although the results of LLO analysis without CST could reflect an ALG5 or ALG6 deficiency, the effect of CST clearly points towards a deficiency of the ALG8 $\alpha$ l,3-glucosyltransferase in both patients. Whereas the LLOs only represent the excess of dolichyl-precursors accumulated in the ER, the $\mathrm{N}$ linked oligosaccharides profile (NLO), extracted from cells grown in the presence of CST, corresponds to the pool of oligosacharides transferred onto the protein. For both patients, the NLO analysis resulted in a reduced amount of GlcNAc$_{2} \mathrm{Man}_{9} \mathrm{Glc}_{2}$ and an increase of the GlcNAc${ }_{2} \mathrm{Man}_{9} \mathrm{Glc}_{1}$ peak, which is consistent with an ALG8 defect (data not shown).

\section{Mutation analysis}

Mutation analysis of the coding regions of the $A L G 8$ gene confirmed this hypothesis. Patient GB0243 is compound heterozygous for the splice mutation c.96-2A $>\mathrm{G}$ in intron 1 and the transversion c.139A $>\mathrm{C}$ in exon 2 , which is translated into the missense mutation p.T47P. The patient carries the polymorphism c.665A $>$ G (p.N222S, rs665278) on the same allele as the missense mutation. The same genotype was also observed in the affected sister. The allele frequency of the polymorphism p.N222S was determined at 0.25 by counting in the Caucasian population (24 out of 98 control chromosomes; results not shown). This confirms the polymorphic nature of this variation. The father of patient GB0243 is homozygous for p.N222S (fig 2).
Screening of the ALG8 gene in patient NL0097 revealed the splice mutation c. $672+4 A>G$ in intron 6 and the missense mutation p.G275D (c.824G $>$ A) in exon 8. All parents were shown to be carriers of one of the respective mutations.

\section{Functional analysis of the splice mutations}

The effect of the splice mutations on the mRNA processing was analysed by comparing ALG8 cDNA amplified from RNA isolated from patients' fibroblasts cultured in the presence or absence of the translation inhibitor puromycin. For GB0243, the p.T47P allele represents at least $90 \%$ of the $A L G 8$ transcripts in the absence of puromycin (fig 3A). Using RNA isolated from fibroblasts incubated with puromycin, both alleles could be amplified in nearly equal amounts (data not shown). The base variation c.96-2A $>\mathrm{G}$ abolishes the regular splice acceptor of exon 2 . Instead, a cryptic splice site $11 \mathrm{bp}$ downstream is used, resulting in an 11-bp deletion and a premature stop at codon p.38 (fig 3B).

Similarly, only the p.G275D allele could be amplified from RNA of fibroblasts from patient NL0097 unless puromycin was added to the cultures. Inhibition of nonsense-mediated mRNA decay (NMD) with puromycin stabilised the abnormal transcript which was lacking exon 6 due to the splice mutation c. $672+4 \mathrm{~A}>\mathrm{G}$.

\section{Functional analysis of the missense mutations}

Due to the high evolutionary conservation of the LLObiosynthesis pathway among eukaryotes, $S$. cerevisiae mutants have been very useful for functional analysis of mutant forms of human ALG proteins. ${ }^{62223}$ To assess the effect of the missense mutations p.T47P and p.G275D on the function of ALG8, complementation assays of yeast strains (S. cerevisiae) deficient for ALG8 were performed. The coding region of ALG8 cDNA was amplified from normal control and patient fibroblasts and cloned into a yeast expression vector under control of the strong GPD promoter. After transformation of yeast strains YG127 (4alg8) and YG98-1d (4alg8wbpl-1), ${ }^{18}$ two independent clones were picked for each plasmid and assayed. 

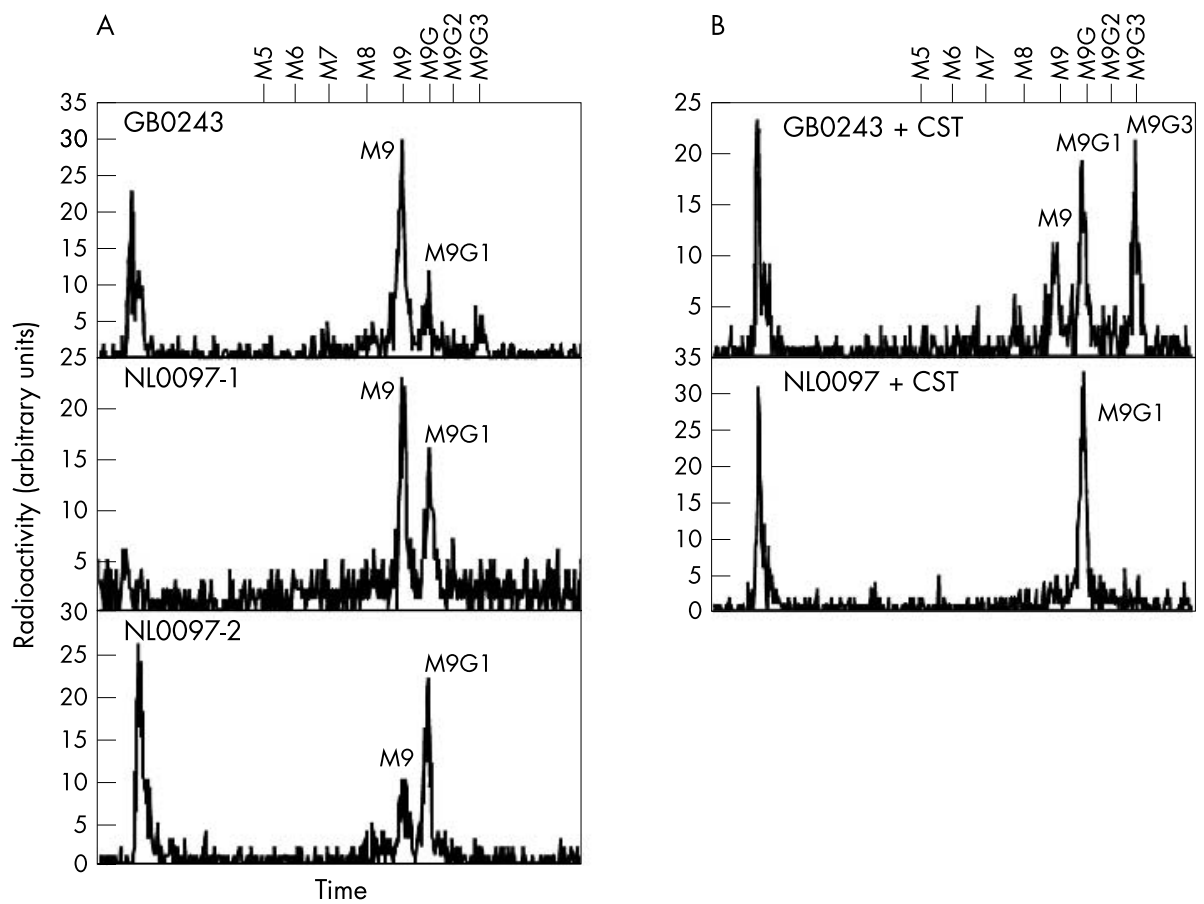

Figure 1 LLO profiles. HPLC separation of $\left[{ }^{3} \mathrm{H}\right]$ mannose labelled LLOs, isolated from patients' fibroblasts (GB0243 and NL0097) cultured in the absence (A) or presence of CST (B). NL0097-1 and NL0097-2 are LLO analysis results from two different extractions and analyses.

The double mutant $\Delta a \lg 8 w b p 1-1$ has a more severe underglycosylation than both single mutants, ${ }^{18}$ resulting in a reduced growth rate at restrictive temperatures. This synthetic phenotype was used to assay the functional effect of p.T47P and p.G275D on ALG8 activity. Incubation of dilution series of YG98-ld transformants at $29^{\circ} \mathrm{C}$ showed a clear difference in complementation efficiency between the yeast and human ALG8 and the two mutant ALG8 constructs. At permissive temperature $\left(23^{\circ} \mathrm{C}\right)$ all transformants showed comparable growth, demonstrating that the dilution series was started with approximately equal amounts of viable cells. With this assay, no difference was observed between complementation with the yeast or human ALG8. In contrast, cells transformed with the mutant ALG8 constructs were more temperature sensitive and grew less well at $29^{\circ} \mathrm{C}$, confirming the deleterious effect of the mutations T47P and G275D (fig 4A).

The underglycosylation of the Aalg8 single mutant yeast strain is less severe and does not result in a growth defect. Therefore, the effect on the degree of glycosylation of the

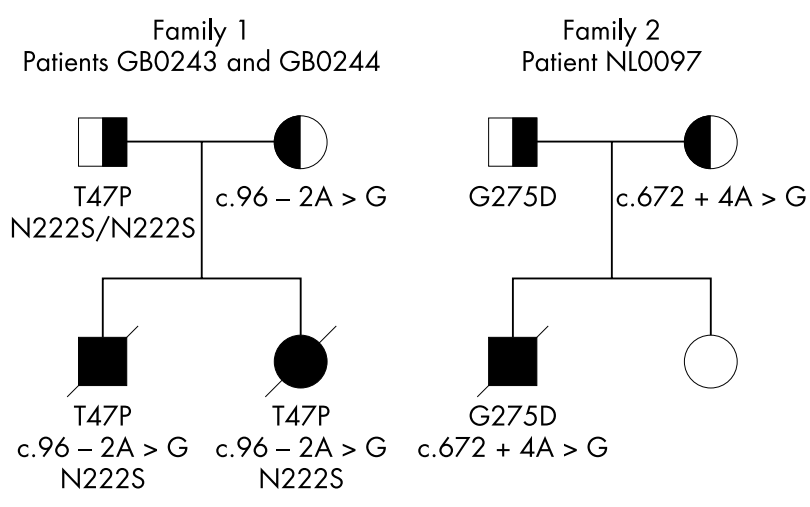

Figure 2 Family tree of the two families with indication of the genotypes. marker protein carboxypeptidase Y (CPY) in the different YG127 transformants was analysed by SDS-PAGE followed by Western blot. The CPY hypoglycosylation pattern with the T47P or G275D mutant constructs was, within experimental variations, comparable to the mock control, while the wild type human $A L G 8$ cDNA conferred a marked restoration of the glycosylation (fig 4B).

\section{DISCUSSION}

We describe three patients from two families with a very severe form of CDG caused by a deficiency of ALG8 (CDG-Ih). The principal pathology in the CDG-Ih patient described so far (this paper and Chantret et $a l^{4}$ ) is a hepato-intestinal presentation, characterised by life-threatening oedema and ascites. The patients described in this paper have a more severe presentation compared to the previously described patient $\mathrm{MP}^{4}$ also presenting mild (GB0243) to severe (NL0097) dysmorphic features and haematopoietic deficiency. Two of the three patients even presented with antenatal symptoms. Although the three patients described here were too young for a definitive conclusion, central nervous system (CNS) abnormalities, a hallmark for all types of CDG-I except CDG-Ib, were not observed. These presentations-predominance of gastro-intestinal problems and the absence of CNS involvement-are reminiscent of CDG-Ib (table 1), but CDG-Ih is, at least in these patients, much more severe and not treatable by mannose therapy.

At present, the variable presentation and severity of the different defects along the ER N-glycosylation pathway is unexplained at the functional level.

The ALG8 defect is characterised by an accumulation of dol-PP-GlcNAc $\mathrm{Man}_{9}$ and dol-PP-GlcNAc $\mathrm{Man}_{9} \mathrm{Glc}_{1}$. The ratio of the two LLO intermediates is variable. This might reflect the differences in glucosidase-glucosyltransferase activities depending on energy and stress during cell culture. ${ }^{21}$ Blocking this shuttle by CST indeed resulted in the accumulation of only dolPP-GlcNAc ${ }_{2} \mathrm{Man}_{9} \mathrm{Glc}_{1}$ in patient NL0097. It is unclear why fibroblasts from GB0243 after 
A

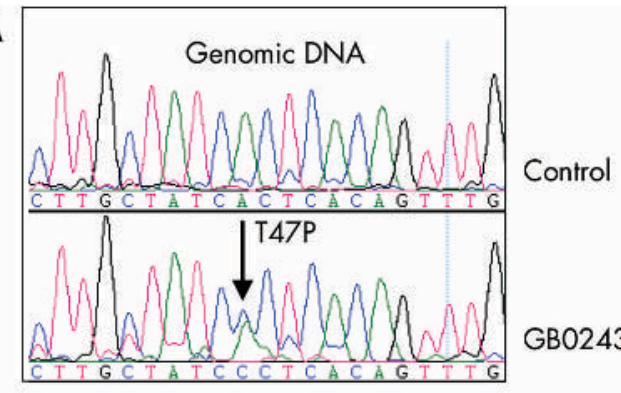

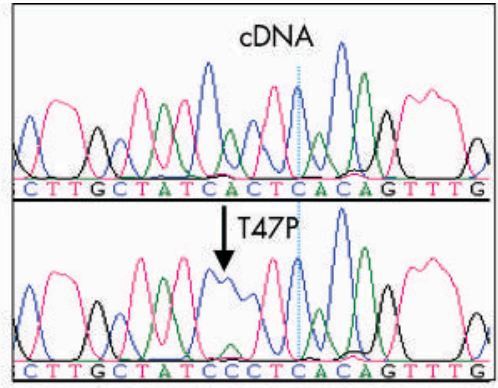

Normal splice site

B

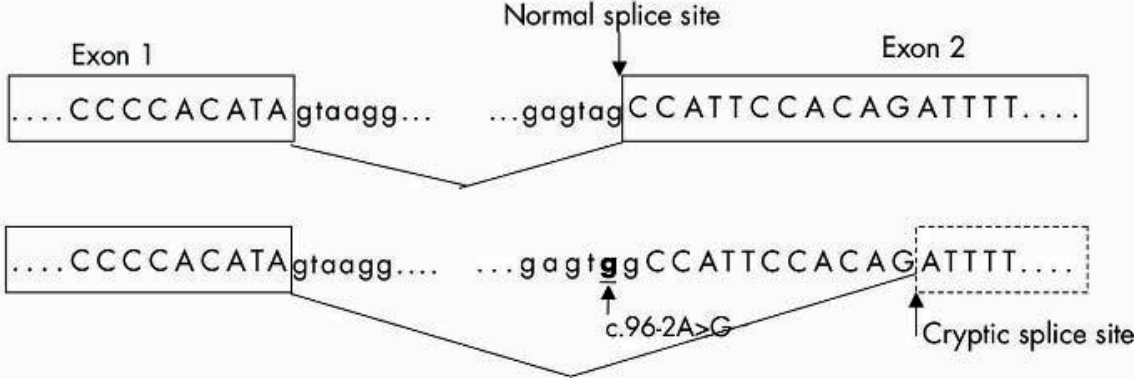

Figure 3 (A) Sequence analysis of the region around position p.T47 on genomic DNA (left panel) and cDNA (right panel) extracted from a normal individual (control) or patient GB0243. (B) The splice mutation c.96-2A>G abolishes the normal splice site, which leads to the use of a cryptic splice site $11 \mathrm{bp}$ downstream of the normal splice site, which results in an 11-bp deletion at the level of the transcript (c.96_106del).

incubation with CST still accumulate both intermediates, in addition to the fully mature PP-GlcNAc $\mathrm{Man}_{9} \mathrm{Glc}_{3}$.

Mutation analysis confirmed the ALG8 deficiency. As expected, both splice mutations c.96-2A $>\mathrm{G}$ and c. $672+4 \mathrm{~A}>\mathrm{G}$ represent a virtual null-allele. The adenine at position -2 in the $3^{\prime}$ splice site of exon 2 is strictly conserved ${ }^{25}$ so the transition c. $96-2 \mathrm{~A}>\mathrm{G}$ must affect splicing. Adenine at position +4 of the splice donor is less conserved $(50 \%),{ }^{25}$ but mRNA analysis clearly indicated mRNA instability for the c.672+4A>G allele of NL0097. Due to aberrant splicing and the creation of a premature stop codon, nonsense-mediated mRNA decay is activated in both cases as demonstrated by the stabilisation of these transcripts by puromycin treatment in culture.

The two missense mutations p.T47P and p.G275D affect conserved positions. The tyrosine at position 47 is highly conserved between the $\alpha 1,3$-glucosyltransferases, ALG6 and ALG8, from different species (fig 5). According to topology predictions, T47 is located in a long peptide motif in the first luminal loop of ALG8, a region which shows conservation
A $29^{\circ} \mathrm{C}$

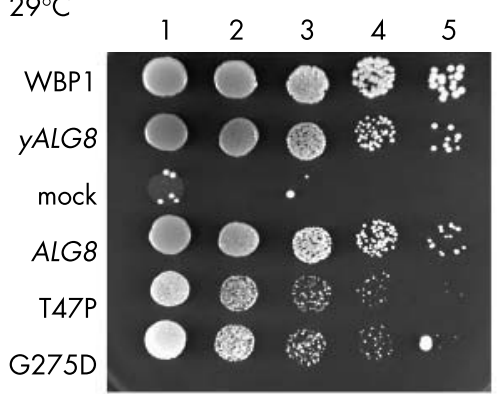

$23^{\circ} \mathrm{C}$

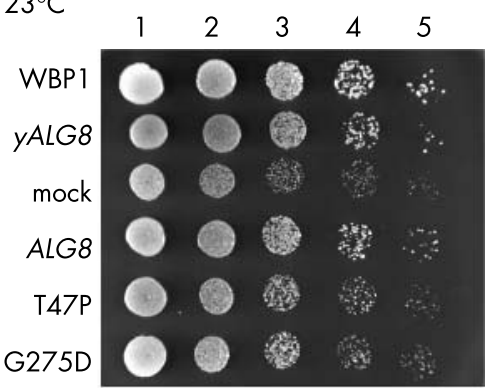

B

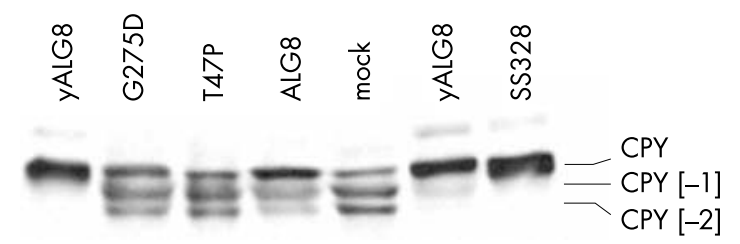

Figure 4 Functional analysis of the missense mutations p.T47P and p.G275D. (A) Dilution series of the S. cerevisiae strain YG98-1d (4alg8 wbp 1-1) transformed with the $\mathrm{p} 426 \mathrm{GPD}$ vector alone (mock), the plasmid pALG8-1 which contains yeast ALG8 (yALG8), human ALG8 (ALG8), mutant human ALG8 (p.T47P and p.G275D) or the YEp352 vector expressing the WBP1 gene. ${ }^{24} \mathrm{~A}$ liquid culture was diluted and spotted to obtain approximately 50000 (1), 5000 (2), 500 (3), 50 (4), and five (5) cells. Plates were incubated for $72 \mathrm{~h}$ at $23^{\circ} \mathrm{C}$ and $29^{\circ} \mathrm{C}$. (B) Western blot analysis of CPY from YG127 (4alg8) transformed with the p426GPD vector (mock), the p426GPD vector expressing yeast ALG8 (yALG8), human ALG8, or mutant human ALG8 (p.T47P and p.G275D) and the parental yeast strain SS328. The bands corresponding to the fully glycosylated mature CPY (CPY) and CPY lacking 1 (CPY[-1]) or 2 (CPY[-2]) glycan chains are marked. 


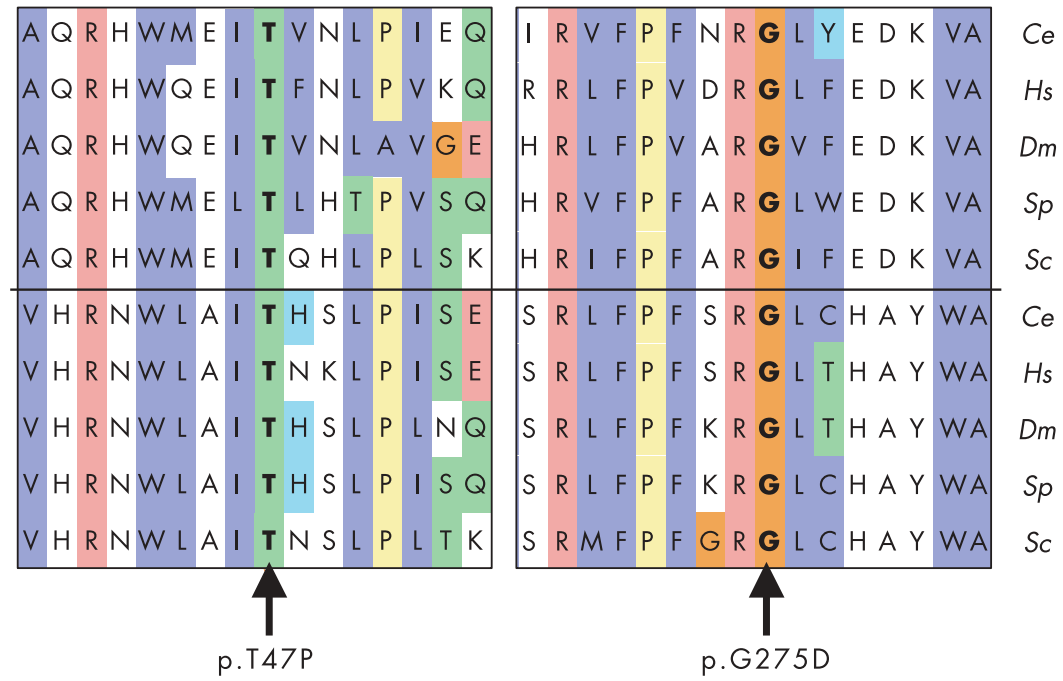

Figure 5 Alignment of the sequence region around mutations p.T47P and p.G275D from ALG6 and ALG8 from human ( $H s), C$. elegans ( $C e)$, D. melanogaster (Dm), S. cerevisiae (Sc) and S. pombe (Sp) (ClustalX scheme in Jalview, modified from PF03155; http://www.sanger.ac.uk/ Software/Pfam/index.shtml).

among the dolP-Man and dolP-Glc dependent mannosyland glucosyltransferases. ${ }^{26}$ Position 275 (glycine) is located in the cytoplasmic loop between the transmembrane domains 6 and 7 and is also conserved between ALG6 and ALG8 of different species but not in other mannosyl- or glucosyltransferases. ${ }^{26}$ Despite these differences in position and conservation, no significant difference has been observed in the effect of the mutations on the ALG8 function. Both in the ALG8-dependent growth assay and the analysis of CPYglycosylation on Western blot, the mutant ALG8 constructs complement less efficiently compared to ALG8 but are comparable with each other. Although these assays are not quantitative, they have been used before to estimate the residual activity of mutant proteins. ${ }^{27}$ Hence, we can conclude that the p.T47P and p.G275D mutant proteins have a similar, low residual activity.

Based on these residual ALG8 activities and the instability of the aberrantly spliced transcripts, the genotypes of the patients GB0243 and NL0097 are comparable. They result in a very severe clinical presentation. Patient NL0097 presented with more dysmorphic features, but the general disease course was similar and resulted in early infant death. This is in contrast with the milder presentation of the previously described patient MP who has two truncating mutations that normally would be considered to be "null" mutations. ${ }^{4}$ Although the single base deletions, c.413delC and c.396insA, observed in patient MP normally result in unstable transcripts due to NMD, the authors identified 10-20\% residual ALG8 mRNA transcript on Northern blot, which might code for functional proteins. We believe that a minimal residual ALG8 activity is essential for viability and that the clinical outcome reflects the sum of the residual activities of the respective proteins.

In summary, the CDG-Ih clinical spectrum includes mild to severe hepato-intestinal problems with or without dysmorphic features depending on the genotype, but no obvious CNS defects.

\section{Authors' affiliations}

E Schollen, L Keldermans, R Reyntjens, G Matthijs, Center for Human Genetics, University of Leuven, Leuven, Belgium

C G Frank, M Aebi, Institute of Microbiology, Swiss Federal Institute of Technology, Zürich, Switzerland
C E Grubenmann, T Hennet, Institute of Physiology, University of Zürich, Zürich, Switzerland

P T Clayton, B G Winchester, Great Ormond Street Hospital for Children and Institute of Child Health, University College London, London, UK J Smeitink, Department of Paediatrics, University Medical Center Nijmegen, Nijmegen, The Netherlands

R A Wevers, Laboratory of Paediatrics and Neurology, University Medical Center Nijmegen, Nijmegen, The Netherlands

This work was supported by TANDEM grant 3238-056350.99 from the Swiss National Foundation and by grant G.0243.98 from the Foundation for Scientific Research (FWO, Flanders). Collaboration occurred in the context of EUROGLYCAN, a network for CDG research funded by the Fifth Framework Program of the European Commission (QLG1-CT-2000-00047).

Conflict of interest: none declared.

Correspondence to: $\mathrm{G}$ Matthijs, Center for Human Genetics, University of Leuven, Herestraat 49, B-3000 Leuven, Belgium; Gert.Matthijs@ uz.kuleuven.ac.be

Received 4 December 2003

Accepted for publication 6 February 2004

\section{REFERENCES}

1 Marquardt T, Denecke J. Congenital disorders of glycosylation: review of their molecular bases, clinical presentations and specific therapies. Eur J Pediatr 2003; 162(6):359-79

2 Jaeken J. Komrower Lecture. Congenital disorders of glycosylation (CDG): it's all in it!. J Inherit Metab Dis 2003;26(2-3):99-118.

3 Grunewald S, Matthiis G, Jaeken J. Congenital disorders of glycosylation: a review. Pediatr Res 2002;52(5):618-24.

4 Chantret I, Dancourt J, Dupre T, Delenda C, Bucher S, Vuillaumier-Barrot S, Ogier de Baulny H, Peletan C, Danos O, Seta N, Durand G, Oriol R, Codogno P, Moore SE. A deficiency in dolichyl-P-glucose: Glc1Man9GlcNAc2-PPdolichyl alpha3-glucosyltransferase defines a new subtype of congenital disorders of glycosylation. J Biol Chem 2003;278(11):9962-71.

5 Wu X, Rush JS, Karaoglu D, Krasnewich D, Lubinsky MS, Waechter CJ, Gilmore R, Freeze HH. Deficiency of UDP-GlcNAc:dolichol phosphate Nacetylglucosamine-1 phosphate transferase (DPAGT1) causes a novel congenital disorder of glycosylation type li. Hum Mutat 2003;22(2): 144-50.

6 Thiel C, Schwarz M, Peng J, Grzmil M, Hasilik M, Braulke T, Kohlschutter A, von Figura K, Lehle L, Korner C. A new type of congenital disorders of glycosylation (CDG-li) provides new insights into the early steps of dolichollinked oligosaccharide biosynthesis. J Biol Chem 2003;278(25):22498-505.

7 Jaeken J, Matthiis G. Congenital disorders of glycosylation. Annu Rev Genom Hum Genet $2001 ; 2: 129-51$.

8 Chantret I, Dupre T, Delenda C, Bucher S, Dancourt J, Barnier A, Charollais A, Heron D, Bader-Meunier B, Danos O, Seta N, Durand G, Oriol R, Codogno P, Moore SE. Congenital disorders of glycosylation type lg is defined by a deficiency in dolichyl-P-mannose:Man7GlcNAc2-PP-dolichyl mannosyltransferase. J Biol Chem 2002;277(28):25815-22. 
9 Grubenmann CE, Frank CG, Kjaergaard S, Berger EG, Aebi M, Hennet T. ALG1 2 mannosyltransferase defect in congenital disorder of glycosylation type lg. Hum Mol Genet 2002;11(19):2331-9.

10 Grubenmann CE, Frank CG, Hulsmeier AJ, Schollen E, Matthiis G Mayatepek E, Berger EG, Aebi M, Hennet T. Deficiency of the first mannosylation step in the $\mathrm{N}$-glycosylation pathway causes congenital disorder of glycosylation type Ik. Hum Mol Genet 2004;13(5):535-42.

11 Hendriksz CJ, McClean P, Henderson MJ, Keir DG, Worthington VC, Imtiaz F Schollen E, Matthiis G, Winchester BG. Successful treatment of carbohydrate deficient glycoprotein syndrome type $1 \mathrm{~b}$ with oral mannose. Arch Dis Child $2001 ; 85(4): 339-40$

12 Niehues R, Hasilik M, Alton G, Korner C, Schiebe-Sukumar M, Koch HG Zimmer KP, Wu R, Harms E, Reiter K, von Figura K, Freeze HH, Harms HK, Marquardt T. Carbohydrate-deficient glycoprotein syndrome type lb. Phosphomannose isomerase deficiency and mannose therapy. J Clin Invest 1998;101(7): 1414-20.

13 Schollen E, Dorland L, de Koning TJ, Van Diggelen OP, Huijmans JG, Marquardt T, Babovic-Vuksanovic D, Patterson M, Imtiaz F, Winchester B, Adamowicz M, Pronicka E, Freeze H, Matthijs G. Genomic organization of the human phosphomannose isomerase (MPI) gene and mutation analysis in patients with congenital disorders of glycosylation type lb (CDG-lb). Hum Mutat 2000;16(3):247-52.

14 Penel-Capelle D, Dobbelaere D, Jaeken J, Klein A, Cartigny M, Weill J. Congenital disorder of glycosylation Ib (CDG-lb) without gastrointestinal symptoms. J Inherit Metab Dis 2003;26(1):83-5.

15 Charlwood J, Clayton P, Johnson A, Keir G, Mian N, Winchester B. A case of the carbohydrate-deficient glycoprotein syndrome type 1 (CDGS type 1) with normal phosphomannomutase activity. J Inherit Metab Dis 1997:20(6):817-26.

16 Messiaen LM, Callens T, Mortier G, Beysen D, Vandenbroucke I, Van Roy N Speleman F, Paepe AD. Exhaustive mutation analysis of the NF1 gene allows identification of $95 \%$ of mutations and reveals a high frequency of unusual splicing defects. Hum Mutat 2000;15(6):541-55.

17 Mumberg D, Muller R, Funk M. Yeast vectors for the controlled expression of heterologous proteins in different genetic backgrounds. Gene 1995;156(1):119-22.
18 Stagliar I, te Heesen S, Aebi M. New phenotype of mutations deficient in glucosylation of the lipid-linked oligosaccharide: cloning of the ALG8 locus. Proc Natl Acad Sci U S A 1994;91(13):5977-81.

19 Guthrie C, Fink GR. Guide to yeast genetics and molecular biology. Methods Enzymol 2002;350.

20 Burda P, te Heesen S, Brachat A, Wach A, Dusterhoft A, Aebi M. Stepwise assembly of the lipid-linked oligosaccharide in the endoplasmic reticulum of Saccharomyces cerevisiae: identification of the ALG9 gene encoding a putative mannosyl transferase. Proc Natl Acad Sci U S A 1996;93(14):7160-5.

21 Spiro MJ, Spiro RG. Potential regulation of $\mathrm{N}$-glycosylation precursor through oligosaccharide-lipid hydrolase action and glucosyltransferase-glucosidase shuttle. J Biol Chem 1991;266(8):5311-7.

22 Korner C, Knauer R, Stephani U, Marquardt T, Lehle L, von Figura K Carbohydrate deficient glycoprotein syndrome type IV: deficiency of dolichylP-Man:Man(5)GlcNAc(2)-PP-dolichyl mannosyltransferase. EMBO J 1999;18(23):6816-22.

23 Imbach T, Burda P, Kuhnert P, Wevers RA, Aebi M, Berger EG, Hennet T. A mutation in the human ortholog of the Saccharomyces cerevisiae ALG6 gene causes carbohydrate-deficient glycoprotein syndrome type-lc. Proc Natl Acad Sci U S A 1999;96(12):6982-7.

24 te Heesen S, Hornig H, Padgett RA, Reiser J, Weissmann C. An essential $45 \mathrm{kDa}$ yeast transmembrane protein reacts with anti-nuclear pore antibodies: purification of the protein, immunolocalization and cloning of the gene. Eur J Cell Biol 1991;56(1):8-18.

25 Aebi M, Martinez-Duncker I, Chantret I, Mollicone R, Codogno P. Sequence requirements for splicing of higher eukaryotic nuclear pre-mRNA. Cell 1986:47(4):555-65.

26 Oriol R, Grunewald S, Schenk B, Burda P, Schollen E, Wevers RA, Jaeken J, de Klerk JB, Berger EG, Matthijs G, Aebi M, Hennet T. Common origin and evolution of glycosyltransferases using Dol-P-monosaccharides as donor substrate. Mol Biol Evol 2002;19(9):1451-63.

27 Imbach T, Rauhut R, Aebersold R, Abelson J, Aebi M, Clark MW. Multi-allelic origin of congenital disorder of glycosylation (CDG)-Ic. Hum Genet 2000; 106(5):538-45 